\title{
The Role of Aortic Stiffness Parameters in Evaluating Myocardial Ischemia
}

\author{
Merve Kumrular ${ }^{\mathrm{a}}$, Pelin Karaca Ozer ${ }^{\mathrm{b}, \mathrm{c}}$, Ali Elitok $^{\mathrm{b}}$
}

\begin{abstract}
Background: Arterial stiffness is a process resulting in deterioration of hemodynamic function of the aorta, a decrease in its compliance and elasticity, caused by the proportional change of components of the extracellular matrix. Although many researches have been done to determine the etiologies of myocardial ischemia in the absence of obstructive coronary artery disease, none of them has investigated the relation between the parameters of aortic stiffness and the myocardial ischemia documented by the exercise stress test. The present crosssectional study aimed to investigate the difference of aortic stiffness parameters between the groups separated by exercise stress test result as positive and negative ischemic findings in the absence of obstructive coronary artery disease.
\end{abstract}

Methods: The present study included 79 patients who were admitted to Istanbul Faculty of Medicine, Department of Cardiology with complaint of chest pain. Forty patients (21 women and 19 men) have ischemic findings on the exercise electrocardiography (ECG) test and 39 patients ( 20 women and 19 men) have normal exercise ECG results. The patients who have positive exercise ECG findings underwent coronary angiography and all the patients had non-obstructive coronary artery disease. Demographic features (age, sex and comorbidities) were statistically similar between the groups. Aortic stiffness measurements (pulse wave velocity, pulse pressure, aortic augmented pressure, augmentation index, systolic pressure-time index, diastolic pressure-time index and subendocardial viability ratio) were done with tonometric methods.

Results: There was no significant difference between the two groups in terms of the aortic stiffness parameters. Systolic blood pressure ( $\mathrm{P}$ $=0.33)$, diastolic blood pressure $(\mathrm{P}=0.24)$, pulse pressure $(\mathrm{P}=0.60)$, systolic pressure-time index $(\mathrm{P}=0.10)$, diastolic pressure-time index $(\mathrm{P}=0.91)$, subendocardial viability ratio $(\mathrm{P}=0.19)$, aortic augmented pressure $(\mathrm{P}=0.87)$, augmentation index $(\mathrm{P}=0.58)$ and pulse wave velocity $(\mathrm{P}=0.56)$ were detected between the two groups. Biochemi-

Manuscript submitted June 27, 2020, accepted July 7, 2020

Published online August 1, 2020

aKirklareli State Hospital, Istanbul, Turkey

bDepartment of Cardiology, Istanbul University Istanbul Medical Faculty, Istanbul, Turkey

${ }^{\mathrm{c} C o r r e s p o n d i n g ~ A u t h o r: ~ P e l i n ~ K a r a c a ~ O z e r, ~ D e p a r t m e n t ~ o f ~ C a r d i o l o g y, ~ I s t a n-~}$ bul University Istanbul Medical Faculty, Topkapi Mahallesi, Turgut Ozal Millet Caddesi, 34093, Fatih/Istanbul, Turkey. Email: pkaracaozer@gmail.com

doi: https://doi.org/10.14740/cr1125 cal parameters were found similar between the two groups. Only lowdensity lipoprotein levels were slightly higher in patients with negative exercise stress test result ( 139 vs. $123 \mathrm{mg} / \mathrm{dL}, \mathrm{P}=0.02$ ).

Conclusion: There is no finding supporting that the aortic stiffness identifies the patients with non-obstructive coronary artery disease but with signs of myocardial ischemia and further investigation of other causes of myocardial ischemia is required.

Keywords: Aortic stiffness; Exercise ECG; Myocardial ischemia

\section{Introduction}

Cardiovascular diseases are the leading cause of mortality and morbidity in the world [1]. Ischemic heart diseases are the largest sub-category of cardiovascular diseases in terms of mortality, morbidity, labor and financial losses [2, 3]. The primary and secondary prevention of ischemic heart diseases is an important part of the general health policies in all countries in the world $[2,4]$.

However, atherosclerotic coronary artery disease is a leading cause, but not the only cause, of ischemic heart disease $[5,6]$. Myocardial ischemia has a wide variety of etiology but shows similar clinical processes and results $[3,7]$. Thus, it is essential to investigate other causes of myocardial ischemia. In the case that the epicardial coronary arteries were found structurally normal with conventional coronary angiography, then the physiology of coronary blood flow was examined and pathological mechanisms, such as microvascular dysfunction and coronary vasospasm were frequently held responsible for the etiology of myocardial ischemia $[5,8]$.

Arterial stiffness is a process that results in a decrease in the aortic compliance and elasticity due to the change in the ratio of extracellular matrix components of the aortic wall $[9,10]$ for many reasons including advanced age, hypertension (HT), diabetes mellitus (DM), hyperlipidemia (HPL), smoking, renal failure, etc., leading to the impairment of some hemodynamic functions $[11,12]$.

Arterial stiffness leads to an increase in systolic blood pressure, an increase in left ventricle afterload, a decrease in diastolic blood pressure and an increase in pulse pressure (PP) $[13,14]$. These hemodynamic alterations may result in increased oxygen demand of myocardial tissue, decreased coronary perfusion pressure and decreased oxygen supply to 
the myocardium, leading to the development of myocardial ischemia $[9,15,16]$.

There are various methods and parameters for the quantitative evaluation of arterial stiffness and the method considered as a gold standard is the tonometrically calculated pulse wave velocity (PWV) [17, 18]. It has been shown that an increased PWV is a cardiovascular risk factor that predicts mortality in renal failure, impaired glucose tolerance, type 2 diabetes mellitus or hypertensive patient groups [19, 20].

The tonometrically calculated pulse wave analysis allows evaluating other parameters associated with arterial stiffness (systolic pressure-time index (SPTI), diastolic pressure-time index (DPTI), "augmentation" index (AIx), aortic "augmented" pressure (AP), etc.) $[17,18]$.

Based on the theoretical information suggesting that aortic stiffness may be a cause of myocardial ischemia, studies were conducted in the literature to indicate the relationship between aortic stiffness and myocardial ischemia [15-17, 21]. These studies concluded that aortic stiffness plays an important role in the severity of ischemia [21] and the earlier presentation of ischemic symptoms [20], and is an important predictor for the prognosis of coronary artery disease $[15,20,22]$. Numerous studies were conducted to explain the myocardial ischemia documented with the exercise electrocardiography (ECG) test in the absence of obstructive coronary artery disease, but no other study on the relationship of myocardial ischemia and aortic stiffness parameters was found. It could not be argued that the only cause of myocardial ischemia is aortic stiffness in the patients included in the study, because of the fact that the risk factors of aortic stiffness are similar with the causes of myocardial ischemia other than atherosclerotic coronary artery disease. There may be more than one etiological factor and such etiologies are not excluded. However, it is possible to examine the relationship between myocardial ischemia and aortic stiffness in the absence of obstructive coronary artery disease.

The aim of the present study was to compare the aortic stiffness parameters between the patients who underwent coronary angiography based on their ischemic exercise ECG test results and not diagnosed with obstructive coronary artery disease and those with normal exercise ECG test results.

\section{Materials and Methods}

The patients aged 25 - 75 years who applied to the cardiology polyclinic for angina pectoris or angina equivalent symptoms, underwent exercise ECG test for ischemia included in the study after their written consent was obtained. For the study, approval was obtained from the ethics committee of the Istanbul Faculty of Medicine. The demographic characteristics of the patients were obtained by taking their medical history during the examinations. All patients underwent a treadmill exercise test (Cardiosoft version 4.14; GE Health-Care System, Freiburg, Germany) by an experienced technician under the supervision of a cardiologist in accordance with the Bruce protocol. Patients were monitored continuously by simultaneous 12-lead ECG before and during exercise and until the end of recovery. In synchrony, 12-lead ECG digital data were continuously recorded. The medication of the patients, including beta-blockers, calcium channel blockers and nitrates was stopped $48 \mathrm{~h}$ before the tests. Patient symptoms, rest and peak heart rate, blood pressure, and any ECG changes were noted. The exercise ECG test result positivity was determined based on the ECG results rather than the symptoms. The ECG criterion for a positive test was $\geq 1 \mathrm{~mm}$ of horizontal or downsloping ST-segment deviation (depression or elevation) in any lead except aVR for at least 60 - $80 \mathrm{~ms}$ after the end of the QRS complex, either during or after exercise [23]. The patients with positive ECG test results underwent coronary angiography. The non-obstructive coronary artery disease by coronary angiography was defined by the presence of a plaque with a $<$ $50 \%$ stenosis on epicardial coronary arteries [24]. The patients were divided into two groups: those with negative exercise ECG result for ischemia, and those with positive exercise ECG result for ischemia but had non-obstructive coronary artery disease at conventional coronary angiography. The aortic stiffness parameters of 40 patients with positive exercise ECG test for ischemia but no angiographic coronary artery disease (21 women and 19 men) and of 39 patients with negative exercise ECG test for ischemia (20 women and 19 men) were evaluated by the tonometric method. The tonometric measurements were performed under the appropriate physical condition with the patients in relaxed and supine positions. Peripheral blood pressure was measured from the patients' left brachial artery. Left radial, left carotid and left femoral arteries were used for the tonometric measurements [18]. The exclusion criteria included atherosclerotic coronary artery disease; the presence of severe ectasi-aneurysm in coronary arteries; heart failure; chronic lung disease which may lead to chronic hypoxia; anemia (hemoglobin < $10 \mathrm{~g} / \mathrm{dL}$ ); active malignancy; active infection; morbid obesity; peripheral artery disease; the failure to perform measurements technically in the tonometric examination.

\section{Tonometric measurements}

The tonometric measurements were performed using a SphygmoCor (AtCor Medical Pty. Ltd, Sydney) branded tonometry device. This device is the most preferred device for this purpose since it can measure the central blood pressure (aortic or carotid) and was used in large clinical studies [18, 25]. This device records the arterial pulse (firstly carotid then femoral) through a piezoelectric sensor in synchronization with ECG.

The central and peripheral artery pressure traces were transferred to the computer environment by the device over the radial artery. The systolic blood pressure, diastolic blood pressure, average blood pressure, PP, heart rate, SPTI, DPTI, subendocardial viability ratio (SEVR), aortic AP and AIx parameters were calculated via the "pulse wave analysis" software (Fig. 1) based on these traces. Then, the distance between the points on carotid and femoral arteries, where the pulses were taken and the measurements were performed, was measured. As specified in the published consensus report [26], the distance was calculated by the "direct measurement" method (direct carotid-femoral artery distance $\times 0.8$ ). This distance was divided by the delay time between carotid and femoral 


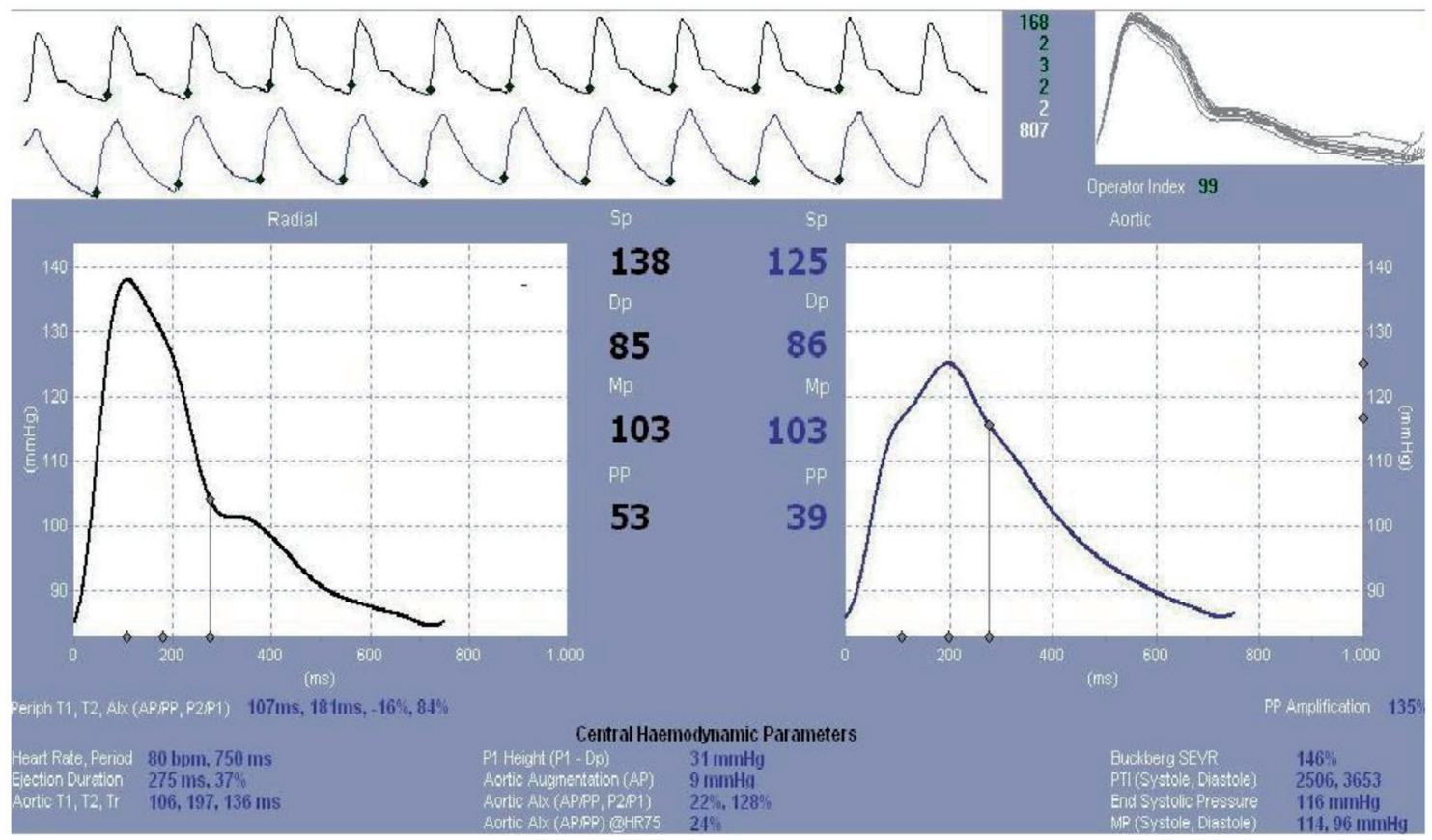

Figure 1. Pulse wave analysis.

artery to find "PWV" [17, 18] (Fig. 2).

\section{Parameters calculated by tonometry}

$P W V$

PWV is obtained by dividing the distance measuring by meter
$(\Delta \mathrm{D})$ between the transcutaneous projections of the regions where measurements are made, by the transit time $(\Delta t)$ between pulse wave graphs obtained from these regions [26]. This measurement allows evaluating the aortic stiffness locally. Aortic PWV is usually measured by the carotid-femoral artery. PWV is not the same at every point of the arterial system and increases towards peripheral arteries [27]. As the severity of arterial stiffness, the PWV value is expected to increase [15].

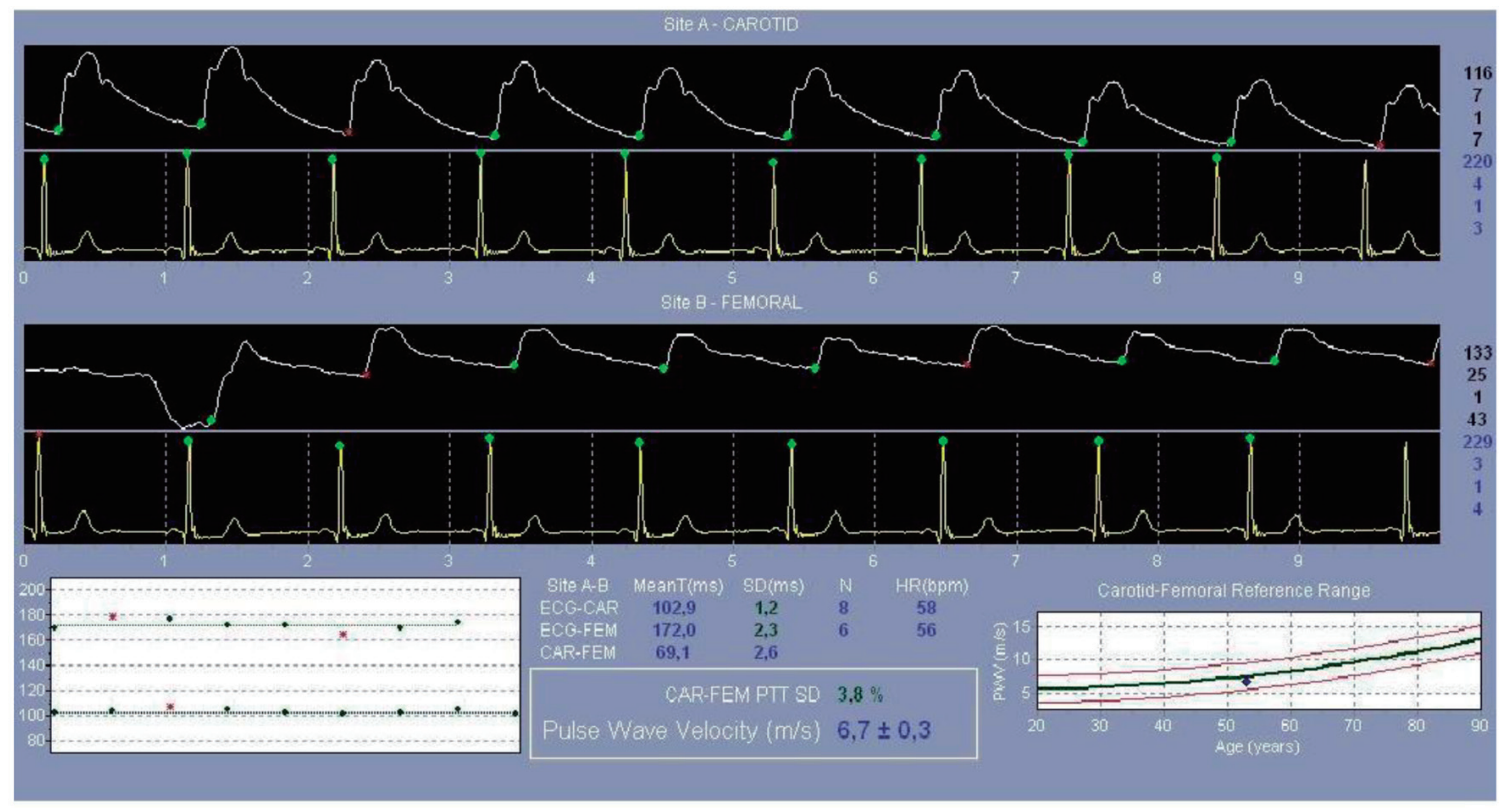

Figure 2. Pulse wave velocity measurement. 


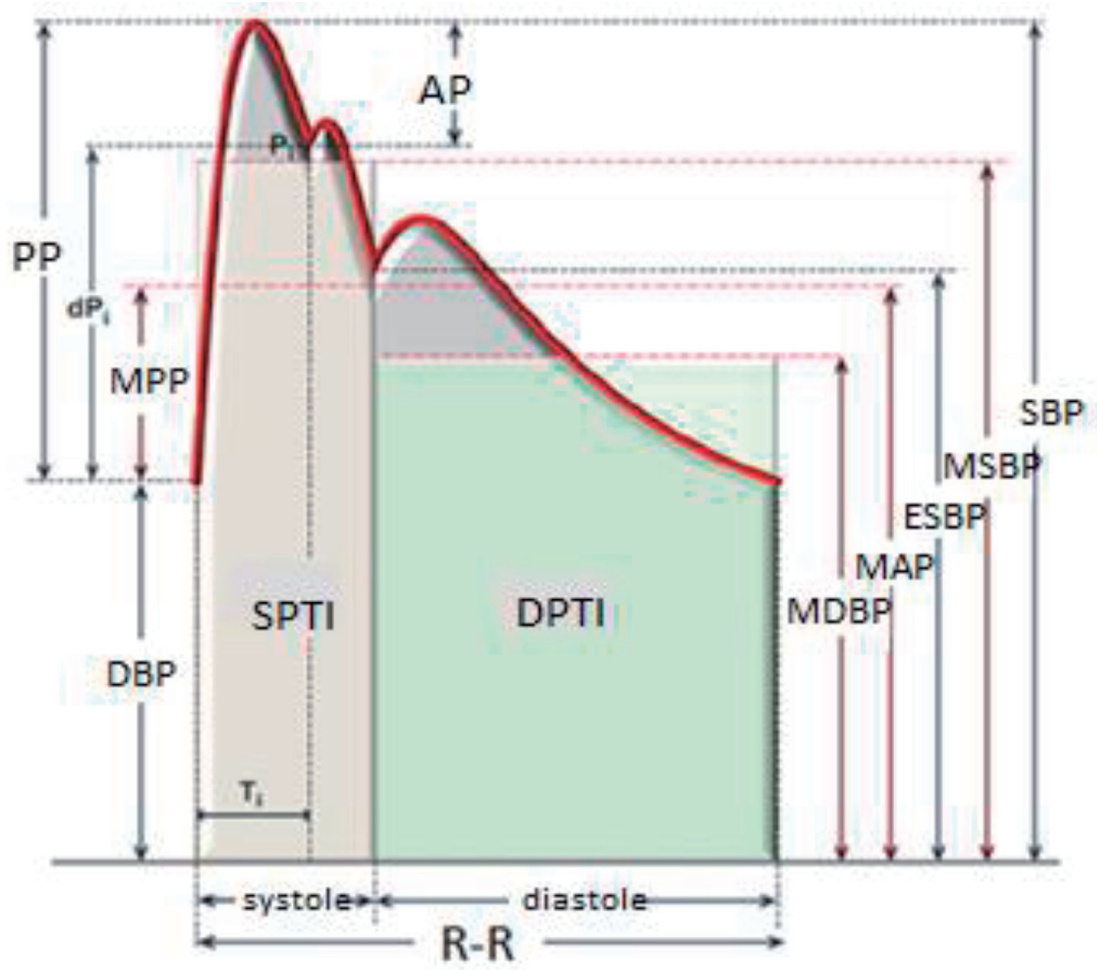

Figure 3. Pulse wave velocity parameters. SBP: systolic blood pressure; DBP: diastolic blood pressure; PP: pulse pressure; ESBP: end-systole blood pressure; AP: augmented pressure; Pi: junction point; Ti: encounter time; dPi: pulse pressure in Ti; MAP: mean arterial pressure; MPP: mean pulse pressure; MSBP: mean systolic blood pressure; MDBP: mean diastolic blood pressure; SPTI: systolic pressure-time index; DPTI: diastolic pressure-time index; R-R: R-R interval (cardiac cycles).

$$
\mathrm{PWV}=\Delta \mathrm{D} / \Delta \mathrm{t}
$$

PWV is now regarded as the gold standard for the measurement of aortic stiffness [26, 27]. It was shown that the PWV calculated based on the measurements at the carotid and femoral arteries is an independent risk factor for cardiovascular mortality and morbidity [28].

\section{Pulse wave analysis parameters}

To examine the final state of the pulse wave formed by the combination of forward wave and reflected wave, some terms should be explained at first. The terms are shown in Figure 3.

1) $\mathrm{AIx}$

The AIx is calculated by dividing the amplitude difference in systolic blood pressure (AP) at the pulse wave, by the PP [27, 29].

$$
\mathrm{AIx}=\mathrm{AP} / \mathrm{PP}
$$

If reflected wave combines with forward wave in the early systolic phase, the systolic blood pressure increases. This increase is associated with how early the waves encounter, and the magnitude of the reflected wave [30]. The AIx is a useful parameter to quantify the role of wave reflection on the high systolic blood pressure values [30, 31].

This index increases due to the impairment of elastic fibers on artery wall secondary to mechanical stress, and is used as a marker for aortic stiffness $[11,28]$.

Heart rate is an important parameter affecting AIx. An increase in heart rate by 10 beats/min causes a decrease in AIx by $3.9 \%$. Thus, to avoid the effect of heart rate, the AIx should be normalized to a standard heart rate [14].

The following formula should be used to normalize the AIx value to a rate of 75 beats $/ \mathrm{min}$.

$$
\text { AIx@75=AIx - } 0.39 \times(75 \text { - heart rate })
$$

\section{2) $\mathrm{PP}$}

PP is the difference between systolic blood pressure and diastolic blood pressure [29]. An increase in systemic vascular resistance causes an increase in both systolic and diastolic blood pressure. While increased arterial stiffness causes an increase in PP [32]. PP was determined as an independent predictor for cardiac mortality and stroke [9].

\section{3) Ejection time}

Ejection time is defined as the period during which the aortic valve remains open during systole [29]. 
Shortening of the left ventricle ejection time is related to a decrease in aortic distensibility, and increased PWV secondary to this $[29,32]$. If the systolic ejection time shortens at a certain heart rate, then the left ventricle has to do its duty in a shorter time but with a higher force [32]. The left ventricle will tend to increase its contractility or heart rate to maintain stroke volume. The increase in heart rate will cause a shortening of both systole time and diastole time (more apparently in diastole time) [29].

\section{4) SPTI}

SPTI is the area under the curve in the pressure-time graph during the systole time of the left ventricle or aorta pressure waveform, i.e. the time from the onset of ventricular systole to the dichrotic notch [29]. It defines the left ventricle afterload. If the mean arterial pressure is high in the ascending aorta in the systole phase, then the left ventricle should contract with a greater force to maintain stroke volume [31]. Therefore, the SPTI is directly related to the myocardial oxygen demand. It depends on ejection time, ejection pressure and myocardial contractility $[9,32]$.

\section{5) DPTI}

DPTI is the area under the curve in the left ventricle pressuretime graph during diastole time [29]. It represents the coronary blood flow and the subendocardial blood presentation during diastole $[14,32]$.

\section{6) SEVR (Buckberg index)}

SEVR is a parameter that is obtained by proportioning the areas under the curve of systolic and diastolic components of the central aortic pulse wave [33]. According to the conventional definition, SEVR is the pressure-time integral ratio derived from the pressure values measured at the aorta and the left ventricle [34]. The numerator of the ratio is the DPTI, which is the area under the curve in the pressure-time graph during diastole. The denominator of the ratio is the SPTI, which is the area under the curve in the same graph during systole [27]. Shortly, it is the balance between the oxygen demand and delivery of subendocardial tissue [18].

The critical value of SEVR was determined as 0.45 . Below this value, the subendocardial and subepicardial blood flow ratio decreased. Above this value, we cannot speak of a direct relation between SEVR and coronary blood flow due to coronary autoregulation [34]. Another factor that affects oxygen delivery as much as the coronary blood flow is the oxygen content of coronary arterial blood. In cases of serious anemia or hypoxemia, even if the coronary flow does not change, the subendocardial oxygen delivery will decrease [34]. To calculate the corrected SEVR value under these conditions, the hemoglobin value, partial oxygen pressure and oxygen saturation $\left(\mathrm{O}_{2} \mathrm{Sat}\right)$ should be adapted to the formula [14]. For the corrected SEVR calculated based on this formula, the critical value is 9 .

$$
\begin{aligned}
& \text { Arterial oxygen content }=1.34 \times \text { Hemoglobin value } \\
& \times \mathrm{O}_{2} \mathrm{Sat}+0.003\left(\mathrm{pO}_{2}\right) \\
& \text { Corrected SEVR }=\text { Arterial oxygen content } \\
& \times(\text { DPTI/SPTI })
\end{aligned}
$$

\section{Statistical analysis}

In the data analysis, the descriptive statistics were presented with mean and standard deviation values. The Mann-Whitney $\mathrm{U}$ test was used to compare differences between the patient groups with positive and negative exercise ECG test results with respect to systolic blood pressure, diastolic blood pressure, PP, SPTI, DPTI, SEVR, aortic AP, AIx, PWV, age, estiamted glomerular filtration rate (eGFR), creatinine, hemoglobin and low-density lipoprotein (LDL) measurement value. The Chi-square $\left(\chi^{2}\right)$ analysis was made to investigate the presence of any accompanying disease such as HT, DM in the patient groups with negative and positive exercise ECG test in the study. In the study, the P value below 0.05 was regarded as statistically significant. The analyses were made using SPSS 22.0 package program.

\section{Results}

The demographic and biochemical data of 40 patients with positive exercise ECG test and 39 patients with negative exercise test are given in Table 1.

In the study, no difference was determined between the patient groups with positive and negative exercise ECG test results with respect to age $(\mathrm{P}=0.71, \mathrm{P}>0.05)$, eGFR measurements $(\mathrm{P}=0.54, \mathrm{P}>0.05)$, creatinine values $(\mathrm{P}=0.4, \mathrm{P}>0.05)$ and hemoglobin values $(\mathrm{P}=0.06, \mathrm{P}>0.05)$.

In the study, it was determined that there was a statistically significant difference between the patient groups with positive and negative exercise ECG test results with respect to LDL measurements, and that, on the contrary, the average LDL level was higher in the patients with negative exercise ECG test results $(139.95 \mathrm{mg} / \mathrm{dL})$ than the patients with positive exercise ECG test results $(123.15 \mathrm{mg} / \mathrm{dL})(\mathrm{P}=0.02, \mathrm{P}<0.05)$.

No statistically significant difference was determined between the study groups with respect to the presence of $\mathrm{HT}(\mathrm{P}=$ $0.89)$, DM $(\mathrm{P}=0.18)$ and HPL $(\mathrm{P}=0.74)$.

There was no statistically significant difference between the study groups with respect to the use of angiotensin converting enzyme (ACE) inhibitor $(\mathrm{P}=0.54)$, beta-blocker $(\mathrm{P}=$ $0.26)$, calcium channel blocker ( $\mathrm{CCB}, \mathrm{P}=0.59$ ), oral antidiabetic drug-insulin $(\mathrm{P}=0.27)$ and statin $(\mathrm{P}=0.84)$. The statisti$\mathrm{cal}$ analysis of the patient groups with respect to the presence of accompanying disease and the drug usage is shown in Table 1.

In present the study, no statistically significant difference was determined between the patient groups with positive and negative exercise ECG test results with respect to systolic blood pressure $(\mathrm{mm} \mathrm{Hg})(\mathrm{P}=0.33, \mathrm{P}>0.05)$, diastolic blood 
Table 1. Clinical Characteristics of the Patients With Positive and Negative Exercise ECG Results

\begin{tabular}{|c|c|c|c|}
\hline Parameters & Positive exercise ECG $(n=40)$ & Negative exercise ECG $(n=39)$ & P value \\
\hline Age, years & $53.25 \pm 10.01$ & $52.33 \pm 11.64$ & 0.71 \\
\hline Male, n (\%) & $19(47.5)$ & $19(48.7)$ & 0.84 \\
\hline Diabetes mellitus, n (\%) & $17(42.5)$ & $11(28.2)$ & 0.18 \\
\hline Hyperlipidemia, n (\%) & $8(20)$ & $9(23.1)$ & 0.74 \\
\hline \multicolumn{4}{|l|}{ Medical treatment } \\
\hline ACEI, n (\%) & $16(40)$ & $13(33.3)$ & 0.54 \\
\hline Beta-blockers, n (\%) & $9(22.5)$ & $5(12.8)$ & 0.26 \\
\hline $\mathrm{CCB}, \mathrm{n}(\%)$ & $8(20)$ & $6(15.4)$ & 0.59 \\
\hline Creatinine, mg/L & $0.80 \pm 0.19$ & $0.76 \pm 0.16$ & 0.40 \\
\hline Hemoglobin & $13.16 \pm 1.48$ & $13.81 \pm 1.6$ & 0.06 \\
\hline $\mathrm{LDL}, \mathrm{mg} / \mathrm{dL}$ & $123.15 \pm 31.25$ & $139.95 \pm 31.09$ & 0.02 \\
\hline
\end{tabular}

ECG: electrocardiography; eGFR: estiamted glomerular filtration rate; ACEI: angiotensin converting enzyme inhibitor; CCB: calcium channel blocker; OAD: oral antidiabetic; LDL: low-density lipoprotein.

pressure $(\mathrm{mm} \mathrm{Hg})(\mathrm{P}=0.24, \mathrm{P}>0.05), \mathrm{PP}(\mathrm{mm} \mathrm{Hg})(\mathrm{P}=0.60$, $\mathrm{P}>0.05)$, SPTI $(\mathrm{P}=0.10, \mathrm{P}>0.05)$, DPTI $(\mathrm{P}=0.91, \mathrm{P}>0.05)$, $\operatorname{SEVR}(\mathrm{P}=0.19, \mathrm{P}>0.05)$, aortic AP $(\mathrm{mm} \mathrm{Hg})(\mathrm{P}=0.87, \mathrm{P}>$ $0.05)$, AIx $(\mathrm{P}=0.58, \mathrm{P}>0.05)$ and $\mathrm{PWV}(\mathrm{cm} / \mathrm{s})(\mathrm{P}=0.56, \mathrm{P}>$ $0.05)$. The statistical analysis of aortic stiffness parameters in the study groups is shown in Table 2 .

\section{Discussion}

Angina pectoris is one of the most common reasons to apply to polyclinics [4]. The prevalence of angina pectoris was evalu- ated by examining the data from 199,494 women and 201,821 men in 31 countries. While there were significant differences between the populations, the average value was determined as $6.7 \%$ in women and $5.7 \%$ in men [35]. Other causes of myocardial ischemia should be investigated in the patient group with angina pectoris and had no obstructive coronary artery disease but exercise ECG result being positive. In a previous study, during the 5-year follow-up, in patients with normal coronary arteries at angiography or plaque without significant stenosis, the incidence of a major cardiovascular event was determined $2.5 \%$ higher in the patient group compared to the normal population. During the10-year follow-up of them,

Table 2. Tonometric Measurement Parameters of Patients With Positive and Negative Exercise ECG Results

\begin{tabular}{llll}
\hline Parameters & Positive exercise ECG $(\mathbf{n}=\mathbf{4 0})$ & Negative exercise ECG $(\mathbf{n}=\mathbf{3 9})$ & P value \\
\hline SBP $(\mathrm{mm} \mathrm{Hg})$ & $129.75 \pm 22.17$ & $129.75 \pm 22.17$ & 0.33 \\
DBP $(\mathrm{mm} \mathrm{Hg})$ & $86.85 \pm 8.63$ & $70.74 \pm 10.21$ & 0.24 \\
PP (mm Hg) & $55.9 \pm 19.35$ & $53.82 \pm 15.71$ & 0.60 \\
$\quad$ SPTI & $2,297 \pm 502$ & $2125 \pm 399$ & 0.10 \\
\multicolumn{1}{c}{ DPTI } & $3,252 \pm 413$ & $3,239 \pm 517$ & 0.91 \\
SEVR (\%) & $146 \pm 30$ & $156 \pm 30$ & 0.19 \\
Aortic AP (mm Hg) & $12.45 \pm 8.44$ & $12.77 \pm 8.48$ & 0.87 \\
AIx @ HR75\% & $24.78 \pm 11.18$ & $23.33 \pm 11.68$ & 0.58 \\
PWV $(\mathrm{cm} / \mathrm{s})$ & $9.09 \pm 2.44$ & $8.75 \pm 2.69$ & 0.56 \\
\hline
\end{tabular}

ECG: electrocardiography; SBP: systolic blood pressure; DBP: diastolic blood pressure; PP: pulse pressure; SPTI: systolic pressure-time index; DPTI: diastolic pressure-time index; SEVR: subendocardial viability ratio; AP: augmented pressure; Alx: augmentation index; PWV: pulse wave velocity. 
cardiovascular death and myocardial infarction developed in $6.7 \%$ of the patients in the group with normal coronary arteries, and in $12.8 \%$ of the patients in the group with minimal coronary artery disease [36]. Also, frequent admission to an emergency department for chest pain, hospitalization and repeated angiography interventions adversely affect the quality of life and increase the financial burden of health services [4, 37]. In another study, epicardial or micro-vascular coronary dysfunction was determined in approximately $60 \%$ of the patients with angina pectoris and structurally normal coronary arteries at coronary angiography [7]. However, as with using the term ischemic heart disease synonymously with the term atherosclerotic obstructive coronary artery disease, it is not suitable to consider any detected myocardial ischemia and observed angina pectoris in the absence of obstructive coronary artery disease, as "micro-vascular" disease or microvascular angina.

Other causes of myocardial ischemia (micro-vascular coronary artery disease, endothelial dysfunction, arterial stiffness, etc.) may be concurrent and in such a case, it is not possible to clearly state which of them is the main cause of myocardial ischemia [8]. However, the examination of aortic stiffness parameters in the patients with myocardial ischemia but had no obstructive coronary artery disease may give an insight into this subject.

Arterial stiffness is a process that results in deterioration of certain hemodynamic functions with reduced aortic compliance and elasticity due to the factors such as advanced age, HT, DM, HPL, smoking and renal failure [16]. In the previous studies, it was indicated that arterial stiffness was shown to be an independent predictor for cardiovascular mortality and allcause deaths $[9,15,20,22,28]$. Development of aortic stiffness leads to an increase in central systolic blood pressure, a decrease in diastolic blood pressure and hence an increase in PP with multiple mechanisms. Such hemodynamic changes can affect cardiac function and myocardial metabolism with several mechanisms [12-14]. It was found that short term blood pressure changes may lead to heart failure, and may be associated with poor prognosis in patients with reduced ejection fraction [38]. Consequently, blood pressure disorder increases the cardiac workload, thus increasing the oxygen demand of the subendocardial tissue. Arterial stiffness is expected to cause or exacerbate the existing myocardial ischemia in terms of hemodynamic consequences.

Although it seems theoretically possible that aortic stiffness can lead to myocardial ischemia, clinical evaluation of the hemodynamic effects of aortic stiffness in the presence of other factors that lead to myocardial ischemia is not straightforward. In the previous studies, it was determined that aortic stiffness is a cause of myocardial ischemia [10, 16, 20, 21, 34]. In a study examining the early occurrence of ischemic ECG signs in patients with atherosclerotic obstructive coronary artery disease in the presence of aortic stiffness, the duration of STsegment depression developed during the exercise ECG test and aortic stiffness parameters were evaluated. Patients with coronary stenosis of $50 \%$ or more detected angiographically in single vessel, two vessels and three vessels were included in the study. Maximum stenosis (critical stenosis) in coronary arteries was specified as $84 \pm 17 \%$ and the ST-segment depression occurrence duration was found to be inversely proportional to the maximum stenosis and the severity of aortic stiffness rather than the prevalence of coronary artery disease (single-vessel, two-vessel and three-vessel) [21].

In our study, the aortic stiffness parameters in the groups with positive and negative exercise ECG test results were examined, and also it was investigated whether the parameters evaluated were significant in favor of arterial stiffness in the group with positive exercise ECG test result compared with the group with negative exercise ECG test result.

In a study conducted with 74 patients, PWV and AIx parameters were evaluated in hypertensive patients with and without temporary myocardial ischemia by monitoring the ambulatory blood pressure and ST-segment on a 24-h basis, and the PWV value was found to be significantly higher in the group with temporary myocardial ischemia $(10.6 \pm 2.4$ to 9.5 $\pm 1.9, \mathrm{P}=0.036)[20]$.

In our study, the average PWV was determined to be 9.09 \pm 2.44 in the group with positive exercise ECG test result and $8.75 \pm 2.69$ in the group with negative exercise ECG test result, thus no statistically significant difference was found $(\mathrm{P}=$ $0.56)$.

Myocardial ischemia can be evaluated quantitatively on the pressure-time curve by the ratio of the areas of the diastolic and systolic intervals under the curve (DPTI/SPTI). This ratio is referred as SEVR [33]. In the literature, in a study conducted with hypertensive patients having ischemic symptoms but no coronary artery disease, the relationship between SEVR and coronary flow reserve was investigated, and it was determined that mean SEVR decreased in the group with decreased coronary flow reserve compared to the group with normal coronary flow reserve [34]. In our study, mean SEVR in the group with positive exercise ECG test result was found to be $146 \pm 30$, while $156 \pm 30$ in the group with negative exercise ECG test result $(P=0.19)$ and the statistical difference was not significant.

\section{Conclusion}

In the present study, we have demonstrated that in patients with non-obstructive coronary artery disease but with signs of myocardial ischemia, it is important to investigate the factors that cause myocardial ischemia other than coronary artery stenosis. It may be beneficial to examine the hemodynamic effects of aortic stiffness parameters after the elimination of other ischemia causes in patients without anatomic coronary artery disease. Further investigation of other causes of myocardial ischemia is required in patients with coronary ischemia but no obstructive coronary artery disease.

\section{Limitation}

One of the major limitations in our study is the lack of investigation of microvascular dysfunction that may lead to myocardial ischemia in the patient group with a positive exercise ECG test result but angiographically normal coronary arteries. In this patient group, microvascular dysfunction may lead 
to ischemic findings in the exercise ECG test. Another major limitation is that the number of patients was low in terms of sample size in the groups. Besides, it was assumed that the patients with negative exercise ECG test results had no obstructive coronary artery disease since coronary angiography was not performed. Because of the sensitivity of the exercise ECG test result was approximately $68 \%$, it was possible that some patients with negative exercise ECG test result also had obstructive coronary artery disease [39].

\section{Acknowledgments}

None to declare.

\section{Financial Disclosure}

None to declare.

\section{Conflict of Interest}

None to declare.

\section{Informed Consent}

All patients were included in the study after obtaining written informed consent.

\section{Author Contributions}

Concept: MK, AE; Design: MK, AE; Data collection and/or processing: MK; Analysis and/or interpretation: MK, PKO, AE; Literature review: $\mathrm{MK}, \mathrm{PKO}, \mathrm{AE}$; Writing: $\mathrm{PKO}, \mathrm{AE}$; Critical review: AE.

\section{Data Availability}

The data supporting the findings of this study are available from the corresponding author upon reasonable request.

\section{References}

1. Leong DP, Joseph PG, McKee M, Anand SS, Teo KK, Schwalm JD, Yusuf S. Reducing the global burden of cardiovascular disease, part 2: prevention and treatment of cardiovascular disease. Circ Res. 2017;121(6):695710 .

2. Davis KB, Chaitman B, Ryan T, Bittner V, Kennedy JW. Comparison of 15-year survival for men and women after initial medical or surgical treatment for coronary artery disease: a CASS registry study. Coronary Artery Surgery Study. J Am Coll Cardiol. 1995;25(5):1000-1009.
3. Shimokawa H, Yasuda S. Myocardial ischemia: current concepts and future perspectives. J Cardiol. 2008;52(2):67-78.

4. Moran AE, Oliver JT, Mirzaie M, Forouzanfar MH, Chilov M, Anderson L, Morrison JL, et al. Assessing the global burden of ischemic heart disease: part 1: methods for a systematic review of the global epidemiology of ischemic heart disease in 1990 and 2010. Glob Heart. 2012;7(4):315-329.

5. Bairey Merz CN, Pepine CJ, Walsh MN, Fleg JL. Ischemia and No Obstructive Coronary Artery Disease (INOCA): developing evidence-based therapies and research agenda for the next decade. Circulation. 2017;135(11):10751092.

6. Agewall S, Giannitsis E, Jernberg T, Katus H. Troponin elevation in coronary vs. non-coronary disease. Eur Heart J. 2011;32(4):404-411.

7. Radico F, Cicchitti V, Zimarino M, De Caterina R. Angina pectoris and myocardial ischemia in the absence of obstructive coronary artery disease: practical considerations for diagnostic tests. JACC Cardiovasc Interv. 2014;7(5):453-463.

8. Pepine CJ. Multiple causes for ischemia without obstructive coronary artery disease: not a short list. Circulation. 2015;131(12):1044-1046.

9. Duprez DA, Cohn JN. Arterial stiffness as a risk factor for coronary atherosclerosis. Curr Atheroscler Rep. 2007;9(2):139-144.

10. Cooper LL, Palmisano JN, Benjamin EJ, Larson MG, Vasan RS, Mitchell GF, Hamburg NM. Microvascular function contributes to the relation between aortic stiffness and cardiovascular events: the Framingham heart study. Circ Cardiovasc Imaging. 2016;9(12).

11. Cavalcante JL, Lima JA, Redheuil A, Al-Mallah MH. Aortic stiffness: current understanding and future directions. J Am Coll Cardiol. 2011;57(14):1511-1522.

12. Sethi S, Rivera O, Oliveros R, Chilton R. Aortic stiffness: pathophysiology, clinical implications, and approach to treatment. Integr Blood Press Control. 2014;7:29-34.

13. Mahmud A, Feely J. Aldosterone-to-renin ratio, arterial stiffness, and the response to aldosterone antagonism in essential hypertension. Am J Hypertens. 2005;18(1):5055.

14. London GM, Guerin AP. Influence of arterial pulse and reflected waves on blood pressure and cardiac function. Am Heart J. 1999;138(3 Pt 2):220-224.

15. Vlachopoulos C, Aznaouridis K, Stefanadis C. Prediction of cardiovascular events and all-cause mortality with arterial stiffness: a systematic review and meta-analysis. J Am Coll Cardiol. 2010;55(13):1318-1327.

16. Salvi P, Parati G. Aortic stiffness and myocardial ischemia. J Hypertens. 2015;33(9):1767-1771.

17. Wohlfahrt P, Krajcoviechova A, Seidlerova J, Mayer O, Bruthans J, Filipovsky J, Laurent S, et al. Arterial stiffness parameters: how do they differ? Atherosclerosis. 2013;231(2):359-364.

18. Chirinos JA. Arterial stiffness: basic concepts and measurement techniques. J Cardiovasc Transl Res. 2012;5(3):243-255. 
19. Steppan J, Barodka V, Berkowitz DE, Nyhan D. Vascular stiffness and increased pulse pressure in the aging cardiovascular system. Cardiol Res Pract. 2011;2011:263585.

20. Dolan E, Thijs L, Li Y, Atkins N, McCormack P, McClory S, O'Brien E, et al. Ambulatory arterial stiffness index as a predictor of cardiovascular mortality in the Dublin Outcome Study. Hypertension. 2006;47(3):365-370.

21. Kingwell BA, Waddell TK, Medley TL, Cameron JD, Dart AM. Large artery stiffness predicts ischemic threshold in patients with coronary artery disease. J Am Coll Cardiol. 2002;40(4):773-779.

22. Benetos A, Thomas F, Joly L, Blacher J, Pannier B, Labat C, Salvi P, et al. Pulse pressure amplification a mechanical biomarker of cardiovascular risk. J Am Coll Cardiol. 2010;55(10):1032-1037.

23. Gibbons RJ, Balady GJ, Bricker JT, Chaitman BR, Fletcher GF, Froelicher VF, Mark DB, et al. ACC/AHA 2002 guideline update for exercise testing: summary article. A report of the American College of Cardiology/American Heart Association Task Force on Practice Guidelines (Committee to Update the 1997 Exercise Testing Guidelines). J Am Coll Cardiol. 2002;40(8):1531-1540.

24. Knuuti J, Wijns W, Saraste A, Capodanno D, Barbato E, Funck-Brentano C, Prescott E, et al. 2019 ESC Guidelines for the diagnosis and management of chronic coronary syndromes. Eur Heart J. 2020;41(3):407-477.

25. Hashimoto J, Imai Y, O'Rourke MF. Indices of pulse wave analysis are better predictors of left ventricular mass reduction than cuff pressure. Am J Hypertens. 2007;20(4):378-384.

26. Laurent S, Cockcroft J, Van Bortel L, Boutouyrie P, Giannattasio C, Hayoz D, Pannier B, et al. Expert consensus document on arterial stiffness: methodological issues and clinical applications. Eur Heart J. 2006;27(21):25882605.

27. Matsui Y, Kario K, Ishikawa J, Eguchi K, Hoshide S, Shimada K. Reproducibility of arterial stiffness indices (pulse wave velocity and augmentation index) simultaneously assessed by automated pulse wave analysis and their associated risk factors in essential hypertensive patients. Hypertens Res. 2004;27(11):851-857.

28. Ecobici M, Voiculescu M. Importance of arterial stiffness in predicting cardiovascular events. Rom J Intern Med. 2017;55(1):8-13.

29. Mitchell GF. Aortic stiffness, pressure and flow pulsatility, and target organ damage. J Appl Physiol (1985). 2018;125(6):1871-1880.
30. Cortez-Cooper MY, DeVan AE, Anton MM, Farrar RP, Beckwith KA, Todd JS, Tanaka H. Effects of high intensity resistance training on arterial stiffness and wave reflection in women. Am J Hypertens. 2005;18(7):930-934.

31. Woodman RJ, Kingwell BA, Beilin LJ, Hamilton SE, Dart AM, Watts GF. Assessment of central and peripheral arterial stiffness: studies indicating the need to use a combination of techniques. Am J Hypertens. 2005;18(2 Pt 1):249-260.

32. Kaess BM, Rong J, Larson MG, Hamburg NM, Vita JA, Cheng S, Aragam J, et al. Relations of central hemodynamics and aortic stiffness with left ventricular structure and function: the Framingham heart study. J Am Heart Assoc. 2016;5(3):e002693.

33. Chemla D, Nitenberg A, Teboul JL, Richard C, Monnet $\mathrm{X}$, le Clesiau $\mathrm{H}$, Valensi $\mathrm{P}$, et al. Subendocardial viability index is related to the diastolic/systolic time ratio and left ventricular filling pressure, not to aortic pressure: an invasive study in resting humans. Clin Exp Pharmacol Physiol. 2009;36(4):413-418.

34. Tsiachris D, Tsioufis C, Syrseloudis D, Roussos D, Tatsis I, Dimitriadis K, Toutouzas K, et al. Subendocardial viability ratio as an index of impaired coronary flow reserve in hypertensives without significant coronary artery stenoses. J Hum Hypertens. 2012;26(1):64-70.

35. Hemingway H, Langenberg C, Damant J, Frost C, Pyorala K, Barrett-Connor E. Prevalence of angina in women versus men: a systematic review and meta-analysis of international variations across 31 countries. Circulation. 2008;117(12):1526-1536.

36. Nichols WW, Denardo SJ, Johnson BD, Sharaf BL, Bairey Merz CN, Pepine CJ. Increased wave reflection and ejection duration in women with chest pain and nonobstructive coronary artery disease: ancillary study from the Women's Ischemia Syndrome Evaluation. J Hypertens. 2013;31(7):1447-1454; discussion 1454-1445.

37. Banks K, Lo M, Khera A. Angina in women without obstructive coronary artery disease. Curr Cardiol Rev. 2010;6(1):71-81.

38. Berry M, Lairez O, Fourcade J, Roncalli J, Carrie D, Pathak A, Chamontin B, et al. Prognostic value of systolic short-term blood pressure variability in systolic heart failure. Clin Hypertens. 2016;22:16.

39. Banerjee A, Newman DR, Van den Bruel A, Heneghan C. Diagnostic accuracy of exercise stress testing for coronary artery disease: a systematic review and meta-analysis of prospective studies. Int J Clin Pract. 2012;66(5):477-492. 